Postprint version of article published in the

International Journal of Law and Psychiatry 30 (2007) 427-443. doi:10.1016/j.ijlp.2007.06.013

\title{
Workers describe the effect of the workers' compensation process on their health: A Québec study
}

\author{
Katherine Lippel \\ Canada Research Chair in Occupational Health and Safety Law, University of Ottawa, Faculty of Law, Civil Law Section, \\ 603 King Edward Street, Ottawa, Canada K1N 6N5
}

\begin{abstract}
This article reports on a Canadian qualitative study designed to examine the workers' experience of the workers' compensation process and to look at the effects of the process on the physical and mental health of claimants. Eighty five in depth individual interviews of injured workers in Québec and six group interviews with workers and worker advocates from Québec, Ontario and British Columbia were analysed to determine the positive and negative impact on claimant health of various steps of the workers' compensation process and of behaviours of significant actors in that process. While superior access to health care and access to economic support both contributed to claimant well-being, various facets of the process undermined the mental health of workers, and in some cases, also had a negative impact on physical health. Primary characteristics of the process that influenced outcomes included stigmatization of injured workers and the significant power imbalance between the claimants and the other actors in the system; the effect of both these mechanisms was tempered by social support. The article describes how caseworkers, physicians, appeal tribunals, employers and compensation boards contribute to the positive or negative impacts on worker health and concludes with recommendations designed to promote the therapeutic aspects of workers' compensation and to curtail those facets that are harmful to worker health. It also has implications for researchers who wish to consider the role of lawyers or compensation in the development or prevention of disability.
\end{abstract}

\section{Introduction}

This article reports on a study designed to examine the workers' experience of the workers' compensation process and to look at the effects of the process on the physical and mental health of claimants. It has been close to two decades since David Wexler and Bruce Winick brought to the fore the Therapeutic Jurisprudence analytical framework that underlines the importance of examining the effect of legal systems and practice on the health of those who appear before the courts (Wexler, 1990; Wexler \& Winick, 1996). Many studies have relied on teachings of Therapeutic Jurisprudence to look at the impact of law and legal practice on juvenile offenders (Weisz, Lott, \& Thai, 2002), psychiatric patients (Roe \& Ronen, 2003), claimants in tort law (Pryor, 2006; Shuman, 1994; Shuman, 2000), the doctor-patient relationship (Hall, 2002-2003), the insurer-patient relationship (Cerminara, 2005) and victims of crime (Desrosiers \& Langevin, 1998); however, few have taken an approach based on social psychology (Carson, 2003). As 
Carson points out, "Analyses or explanations in terms of the distribution of power or other resources, or in terms of ideologies and the control of meanings, are unlikely to feature in TJ papers" (Carson, 2003, p. 126). Fewer still have examined administrative law, including social legislation through a Therapeutic Jurisprudence lens.

Even before the term Therapeutic Jurisprudence was coined, Terence Ison (1986) addressed the issue of workers' compensation structures and their impact on the health of claimants. At that time, as they are today, medical evaluation practices were a key component to the adjudication of compensation claims, and Ison eloquently demonstrated ways in which the medico-legal process could give rise to anti-therapeutic consequences.

A review of occupational health literature shows that research from the health sciences hypothesizes that antitherapeutic consequences are attributable to the involvement of a patient with a member of the legal profession (Braun, Doehr, Mosqueda, \& Garcia, 1999) or access to compensation (Cassidy et al., 2000), while legal researchers have described the anti-therapeutic effects of the intervention of health professionals in the compensation process (Ison, 1986). Literature on vocational rehabilitation and return to work has identified pending litigation as a factor that hinders the rehabilitation process (Baril, Clarke, Friesen, Stock, \& Cole, 2003). In the field of injury compensation, controversy still surrounds the concept of secondary gain, both in the legal and the medical literature (Shuman, 2000, pp. 887-888).

Until recently, few studies have examined from the point of view of the injured workers the workers' compensation process (Beardwood, Kirsh, \& Clark, 2005; Kirsh \& McKee, 2003; Roberts-Yates, 2003; Strunin \& Boden, 2004) or the return to work process (Roberts-Yates, 2003; Sager \& James, 2005; Tarasuk \& Eakin, 1995), although some studies have included both workers and employers when studying the return to work process (Baril et al., 2003; Eakin, MacEachen, \& Clarke, 2003). In a seminal article on approaches to the study of the social consequences of occupational injury and disease, Dembe proposes a model that takes into consideration a broad variety of systemic factors that need to be studied if we are to understand the process by which work injury, its treatment and the compensation process contribute to ill health (Dembe, 2001). The present study looks specifically at the compensation process in order to identify aspects that positively or negatively affect the workers' experience and potentially their health.

In order to understand the results of this study it is necessary to understand the basic premises and structures of the Québec workers' compensation system, a system that closely resembles those of other Canadian provinces ${ }^{1}$ and shares many similarities with those of Australia and the United States. The Québec workers' compensation system is a "nofault" system in the sense that access to compensation is available regardless of proof of fault and regardless of legal liability of the employer. Workers who are covered by the system, over $90 \%$ of employees in Québec, have no choice but to claim under the workers' compensation system in the event of occupational injury or illness and all forms of civil liability of the worker's employer is precluded. Protection from law suit extends to all employers whose workers have coverage under the system, although in Québec lawsuits remain possible against employers other than the worker's own employer, in exceptional circumstances, as in cases of criminal negligence ${ }^{2}$ while other provinces preclude all law suits against any insured employer including doctors who are protected from malpractice suits. ${ }^{3}$ The "no-fault" nature of the scheme does not imply that no fault was committed by the employer, only that the existence of such a fault is irrelevant in the adjudication process, so that at no time in the course of the compensation process will the employer be blamed for causing the injury or illness, regardless of the circumstances, and this is essentially true with regard to the worker's behaviour, although an injury that is not serious and that is attributable exclusively to the worker's gross negligence is excluded from coverage. ${ }^{4}$

The claim is administered by the Commission de la santé et de la sécurité du travail or CSST, a public administratorinsurer financed exclusively by employer premiums. No private insurers are involved in workers' compensation in any Canadian province. All decisions of the CSST adjudicators are subject to internal review, without a hearing, and to an external appeal board, which holds a public hearing, the Commission des lésions professionnelles (CLP). Both the worker and the employer have the right to appeal any CSST decision. Unlike the situation in most North American jurisdictions, the CSST is bound by the opinion of the treating physician with regard to decisions on most medical issues, including diagnosis, treatment, date of stabilization of the injury, functional limitations and degree of permanent

\footnotetext{
' For information on workers' compensation legislation in all Canadian jurisdictions see the Website of the Association of Workers'

Compensation Boards of Canada, consulted on November 24th 2006: http://www.awcbc.org/english/.

${ }^{2}$ An Act Respecting Industrial Accidents and Occupational Diseases, R.S.Q., c. A-3.001, (ARIAOD) s. 441.

${ }^{3}$ Kovach v. British Columbia (Workers' Compensation Board), [2000] 1 S.C.R. 55.

${ }^{4}$ ARIAOD, s. 27.
} 
impairment ${ }^{5}$ as well as on early return to work issues. ${ }^{6}$ If either the employer or the CSST disagrees with the opinion of the treating physician, it may be set aside through a complex procedure that includes obtaining a second medical opinion, submitting that written opinion to the treating physician and then, if this does not bring about a change of opinion on the part of the treating physician, both medical opinions are sent to a third medical evaluator from the Bureau d'évaluation médicale. Many medical opinions may be questioned in the same file, so that it is not uncommon for workers to be submitted to a large number (in some cases dozens) of medical evaluations that are not in any way part of the therapeutic process. Decisions regarding these medical opinions can then be appealed to the CLP. Judicial review is considered by law to be an extraordinary measure and is rare.

In recent years the system has become increasingly adversarial. In 2004-2005 there were 27,141 appeals filed with the CLP (CLP, 2005), a huge number when compared to the appeals filed in the equivalent tribunal of Ontario, the Workers' Safety and Insurance Appeal Tribunal, which received 3922 appeals in 2003 and 3781 appeals in 2004 (WSIAT, 2005, p. 35). Even compared to its own record, appeals are up by close to 30\% in Québec since 1999 (CLP, 2000). The CSST received 152,799 claims in 2004, (CSST, 2005). Although appellants are unlikely to be the same individuals as claimants in a given year, and even taking into consideration the fact that many different decisions may be contested in a given file, the number of appeals still seems extraordinary, particularly in the context of a no-fault system designed to avoid controversy and to preserve harmony between the worker and the employer (Lippel, 1986).

Although experience rating is used in both provinces as a cost incentive to encourage employers to act more responsibly, the way the system works in Québec seems to encourage a great deal of litigation, as every dollar spent on a worker, be it for benefits, health care, rehabilitation or permanent disability, will have a direct effect on the assessment rates of the medium and large employers. Since 1998, even the small employers are encouraged to share their risks by joining a mutual administrator (mutuelle de prévention), and now small businesses who are members of a mutuelle are pressured to contest claims as the assessments of the mutuelles, as well as those of the larger firms, vary according to the compensation experience in previous years, which provides a clear incentive to employers to contest claims in order to keep costs down. Although few studies have examined mechanisms by which experience rating actually affects prevention behaviour (Tompa, Trevithick, \& McLeod, 2007), there is some evidence that only the very large firms invest in health and safety professionals, while the others will invest in claims management specialists (Thomason \& Pozzebon, 2002).

Unlike the situation in the United States, where claims behaviour is driven by accessibility of health care, even though that health care may sometimes be inadequate (Dembe, 1999), all Canadian residents have access to public health insurance, and workers whose claims are denied will nevertheless access free health care, although availability of specialists and some services varies geographically, and long waiting lists may exist for non-emergency care.

\section{Methods}

In a previous study (Lippel, 1999b) we relied on classical legal research methods, including analysis of comparative legal literature and case law regarding disability engendered by the workers' compensation system, to provide an overview of the therapeutic and anti-therapeutic consequences of the compensation system. The article concluded that victims of work accidents were being blamed in a broad range of situations in what was ostensibly a no-fault system.

This study relied on participatory action research methods (Baum, MacDougall, \& Smith, 2006), made possible by a research partnership with non-profit organisations that had a long history of advocacy for the rights of injured workers. We undertook a qualitative study to better understand the ways in which specific steps in the compensation process and specific actors in and around the compensation system affected, either positively or negatively, the self-reported health of the worker-claimant. The study included eighty-five face-to-face semi-structured interviews with injured workers in Québec, and these interviews were preceded by a group interview with twenty-five injured workers, during which injured workers assisted in defining the research questions and the interview schedule. The article is also informed by five other group interviews, with representatives of injured workers in Québec (three), Ontario (one) and British Columbia (one). Participants were asked to describe their experience as claimants, or, in the case of the advocates, the experience of claimants they represented, and more specifically to explain how the workers' compensation process had positively or negatively affected the workers' health. Interviews were conducted by skilled interviewers who were also

\footnotetext{
${ }^{5}$ ARIAOD, s.s. 212 and 224.

${ }^{6}$ ARIAOD, s. 179.
} 
familiar with the legal aspects of the workers' compensation system. The study protocol was approved by the research ethics committee of the Université du Québec à Montréal.

Preliminary results (Lippel, Lefebvre, Schmidt, \& Caron, 2005; Lippel, Lefebvre, Schmidt, \& Caron, 2007) were presented at several meetings attended by both the research subjects and other injured workers, and workers confirmed that the preliminary report accurately reflected their experience. Over 100 workers attended these presentations and all were invited to bring forward comments or criticism of the presentations and the documentation. While the research team and partner associations received many comments to the effect that workers recognized their experience in the presentation and the report, no one provided dissenting comments or expressed the feeling that their point of view had been set aside. Nor did anyone suggest changes to the report as presented.

\subsection{Individual interviews}

All interviews took place in 2003 and 2004. The individual interviews lasted between one and a half and three hours. The majority of the interviews were in French, ${ }^{7}$ the working language in Québec, although workers could choose to be interviewed in either French or English and four interviews were conducted in English. All but one of the interviews were audio recorded, eighty-two interviews were transcribed and analysed with N'Vivo software. Inter-rater coding reliability was ensured by a collectively developed coding scale and several sessions in which all members of the research team coded the same interviews. A grounded-theory approach (Glaser \& Strauss, 1967) was used to glean meaning from the data.

Subjects were recruited from a variety of sources, including referrals by research partners and unions, as well as advertisements, in French and English, placed in law offices, medical clinics and newspapers. Inclusion criteria were broad. Any worker who had made a workers' compensation claim in Québec was eligible, and the sample included a few claimants whose original claims dated back to the previous workers' compensation legislation, which was replaced in 1985. The vast majority of the participants had claims that were either currently active or recently settled. A broad inclusion criteria allowed for better understanding of effects of specific aspects of the system, as it was possible to compare the experience of workers governed by different rules. Although the sample was not intended to be representative of injured workers in general, effort was made to ensure the broadest possible spectrum of viewpoints and experiences, and recruitment stopped only when saturation was attained.

Forty eight percent of the sample were women, approximately half the participants were unionized, French was the first language of seventy eight percent, English was the first language of $7 \%$ and $15 \%$ had other languages as their first language. Eighty-two percent had sustained injuries as a result of an accident while $18 \%$ had claimed for an occupational disease. The initial claim of $79 \%$ of the interviewees was accepted in whole or in part by the CSST, although in $61 \%$ of accepted cases some issues remained litigious. Subjects had suffered from a broad range of injuries, including back injuries, upper extremity disorders, various other musculo-skeletal disorders, burns, fractures, head injuries, respiratory disease, poisoning by neuro-toxic substances, loss of an eye and post-traumatic stress disorder.

Interviews were conducted in six regions of Québec, including urban centres, rural areas and out-lying areas where primary industries such as mining and forestry were dominant.

\subsection{Group interviews}

The group interview with injured workers who were members of associations that were research partners took place in 2002 and was designed to shape the research questions and the analysis. Group interviews with worker representatives in Québec included two group interviews with staff from non-profit associations that have played an advocacy role for injured workers, one of these interviews focussed on health effects of the system, while the other looked at specific challenges to workers who were precariously employed. A fourth group interview sought to examine the viewpoint of lawyers who were experienced in the representation of injured workers. As most participants in the group interviews had over ten years experience with the compensation system, this allowed for a historical perspective that would not have been possible with only the individual interviews. The group interviews also allowed for triangulation, the perspective of the community groups and the lawyers being sometimes similar but sometimes quite different both from that of the other and from that of the workers.

\footnotetext{
${ }^{7}$ Quotes from these interviews that are cited here have been translated by the author.
} 
Finally one group interview was held in Toronto and another in Vancouver with worker representatives (lawyers and representatives of unions and the office of the worker advisor) in order to verify the extent to which the experiences described in Québec resembled or differed from those prevailing in Ontario and B.C., but also to identify system differences that could account for differences in the experience of claimants.

The primary objective of the study was not just to describe the experience of the workers and the self-reported effects on their health of the compensation process but also to identify specific steps in the process and specific actors in the system that had a positive or negative impact on that experience.

\section{Results}

\subsection{How the system affects workers' health}

Workers spontaneously identified numerous examples of negative health effects, although there were also illustrations of positive health effects associated with the workers' compensation claim. Most comments addressed mental health issues, although in a few cases physical health outcomes were affected by the process.

\subsection{Physical health outcomes}

Physical health was positively affected by more expeditious access to health care, the CSST exerting influence on waiting lists and access to specialists:

"The date I was given for my surgery was November 2002. I then called my caseworker at the CSST and she said,

'Whoa!' 'November 2002,' she said, 'No, no, no, no, no.' I got called back by the hospital two days later, saying, 'OK, your surgery is now August.' So that's a good thing about it — queue-jumping."

In outlying regions the health care offered to an injured worker was significantly better than that which was available under the public system, as costs to facilitate consultations with specialists, including psychiatrists, neuropsychologists and pain specialists, unavailable locally, were assumed by the CSST. Even in urban areas, workers who were eligible for workers' compensation were advantaged by speedy access to care from privately owned facilities providing physiotherapy, occupational therapy and care by a psychologist, and other services known to be more difficult to access under the public health care system (Fougeyrollas et al., 1999).

Negative effects on physical health were attributed primarily to premature return to work when a compensation claim was refused or when benefits were ended prematurely, resulting in aggravation of the initial injury. Often mentioned as well, were painful medical examinations that provoked recurrences and tardy access to physiotherapy and other treatments engendered by initial refusal of a claim by the CSST.

\subsection{Mental health outcomes}

By far the most prevalent health effects attributed by the workers to the compensation process were those reported to affect the mental health of claimants. Of the eighty-two participants whose interviews were transcribed, only four had claims for mental health problems as an initial injury (both acute and chronic stress claims may be eligible for compensation in Québec (Lippel, 1999a), yet the majority of subjects interviewed reported that the experience as a workers' compensation claimant had negative effects on their mental health. Although these problems were described in great detail and in multiple ways, here we will focus on three categories we used to identify the negative mental health effects attributable to the process: an examination of feelings and emotions; self-reported episodes of depression, anxiety, paranoia or treatment in a psychiatric facility; and talk of suicide.

\subsubsection{Feelings and emotions}

All expressions of feelings and emotions described by our subjects were recoded in order to glean a global portrait of the experiences of these workers. They were first subdivided into expressions of positive (twenty-three) and negative (ninety-three) emotions or feelings, many of which had been expressed by several subjects. Even those emotions categorized as positive were not necessarily the expression of a positive perception of the process. While some were "reassured" by the financial support provided by the CSST, "felt vindicated" by a successful appeal, "felt understood" 
Table 1

Fear attributable to the injury and the process

\begin{tabular}{|c|c|}
\hline Source of fear attributable to the injury & Source of fear attributable to the process \\
\hline Unknown evolution of a life threatening disease & Refusal of compensation resulting in poverty \\
\hline Uncertainty about post-injury abilities & Surveillance by private investigators \\
\hline Painful and dangerous treatment & Impact on the entire family of stress from the claims process \\
\hline Potential job loss & Medical evaluations \\
\hline Loss of enjoyment of life & $\begin{array}{l}\text { Fear of being unable to make oneself understood by medical evaluators, caseworkers, } \\
\text { appeal commissioners etc. }\end{array}$ \\
\hline
\end{tabular}

by the appeal commissioner, others were "relieved" or "proud" to have made it through the entire process without giving up, "lucky" to be supported by their union, or "pleased" to be able to share their experience with other workers who had suffered from the same type of difficulties. Negative expressions of emotion were far more numerous and often very poignantly expressed. "It made me vomit", "I'm not worth much per pound", "I felt like I was going crazy", "I wouldn't wish it on anybody", "I screamed with rage", "it was like being branded with a red hot iron", "I was in a panic", "I felt trapped", “vulnerable", "guilty", "frightened", "punished”, "rejected", "humiliated", "tricked” and, in many cases, "tired of fighting". These expressions of feeling/emotion were then re-examined in order to better understand the mechanisms at play. An examination of statements about fear illustrates the complexity of each expression of emotion.

A simple expression like "I was afraid" harboured layers of information about the effect of the process on health. Twenty-one different sources of fear were identified, some attributable to the injury or illness, others attributable to the process. Those listed in Table 1 were the most frequently cited.

While not necessarily indicative of mental illness as such, the expression of these different emotions contributed to a portrait of mental distress shared by the vast majority of our subjects.

\subsubsection{Mental health problems}

When a serious injury affects a person's sense of self, it is often the case that it affects not only physical but mental health. Some of the people we met with, whose claims were accepted by the CSST without difficulty, suffered from depression or anxiety as a result of the effects of the illness itself, particularly when the illness was life threatening, as in the case of beryllium poisoning, or when consequences of the injury were extremely severe and painful, as in the case of third degree burns to the whole body or chronic pain syndrome. However, many people, men as well as women, were treated for mental health problems attributable not to their original employment injury, but to the repercussions of their compensation claim. As a result of these problems, some were treated by a health care professional, either a psychiatrist in a psychiatric facility or as an outpatient or by a psychologist, while others remained silent about their psychological suffering for fear of inviting new difficulties and increased stigmatization. Excluding the four people for whom the original injury was psychological in nature, but including the people who considered suicide and who spoke of depression (but not including those who spoke of suicide but not of depression), fifteen women (40\%) and eleven men (26\%) told us they had had episodes of what they reported as "depression" associated with both the injury and the process, or associated exclusively with the process. This count excludes the people (five women and seven men) who spoke of a "discouraging experience" and a fear of "going into depression" or who considered their depression to be solely the result of the injury.

\subsubsection{Suicidal thoughts}

Four women (10\%) and thirteen men (30\%) spoke to us about thoughts of suicide. These numbers do not include the people who went out of their way to stress that they had not contemplated suicide. They are remarkable given that no mention of suicide was ever made by the interviewers; no questions were asked concerning suicide. The frequency with which suicide was discussed was similar in both those claimants referred by research partners and those who contacted us after having seen an advertisement. The lawyers and worker representatives we met with also discussed suicide as a significant preoccupation in their law practice, and several shared with us their strategies to help prevent their clients from committing suicide. These strategies were described as an intrinsic part of a practice in workers' compensation law. 


\subsection{Possible explanations of the adverse mental health effects}

Although the vast majority of workers interviewed described negative experiences in the compensation system, some came through the process relatively unscathed, while others said they were actually more disabled by the mental consequences of the process than by the initial injury itself, a finding also identified in an Australian study (RobertsYates, 2003). In this section we will examine the workers' descriptions of their experience in order to identify factors that were either destructive to or protective of their mental health. We identified three factors as being particularly prevalent and significant: issues surrounding stigma, the imbalance of power, and access to a person of trust who provided social support.

\subsubsection{Stigma}

More than half of the workers interviewed described, in one way or another, the stigmatization attached to the status of injured worker, the prejudice against injured workers, and the stereotypes that painted all injured workers as fraud artists abusing the system. We use the term stigma as defined by Link and Phelan (2001, p. 363): "the co-occurrence of its components - labelling stereotyping, separation, status loss, and discrimination - and further indicate that for stigmatization to occur, power must be exercised".

The frequency with which this subject arose takes on significance both because it was never raised by the person conducting the interview and because it is an issue that has been frequently identified in studies of workers who describe the effect of the compensation process. In Ontario, researchers who have studied the experience of injured workers (Beardwood et al., 2005; Kirsh \& McKee, 2003), as well as others who have investigated the perspective of both workers and employers regarding return to work (Eakin, 2005; Eakin et al., 2003) reported on similar experiences of stigma.

Australian researchers have also reported that stigma is an important factor in the experience of injured workers (Sager \& James, 2005:133), and show how this led a worker to "try to do more sometimes than you should" or to take "annual leave and long-service leave as a way of coping emotionally with the negative attitude of co-workers". Another Australian study (Roberts-Yates, 2003:906) also reported on the stigma associated with the status of workers' compensation claimant and recommended education of "work-mates and the community in order to promote a nonjudgemental response to 'invisible' injuries". Strunin and Boden in their study of American workers identified similar issues (Strunin \& Boden, 2004).

Many of the workers interviewed were in pain, and felt they were disbelieved with regard to their pain and that as a result they were seen as malingerers. The need for legitimacy that has been identified in workers who have suffered back injuries (Tarasuk \& Eakin, 1995), and persons suffering from upper extremity disorders (Reid, Ewan, \& Lowy, 1991) is also clearly present in other workers who feel they are stereotyped as being dishonest simply for having filed a workers' compensation claim for a lost time injury. As one worker described it in our study, "it's like you've got a label on your forehead. You're marked as an opportunist".

In our study, workers reported feeling they were being treated like criminals because, although they suffered from a clearly recognized and diagnosed occupational disease, it had no external signs. This was also the case for those who suffered from pain that they reported to be incapacitating but that could not be measured and was therefore invisible to the CSST, the employer, physicians, colleagues and neighbours, and sometimes even to family members. Some with visible injuries also felt stigmatized for having simply filed a claim for benefits or received compensation from the CSST, for having tried unsuccessfully to return to work or attempted to have their rights recognized by the appeal tribunal.

Workers attributed their feelings to a variety of comments and behaviours of a broad range of actors including: friends, co-workers, employers, private detectives, compensation caseworkers, rehabilitation counsellors, attending physicians, compensation and employer medical evaluators, lawyers and administrative tribunal adjudicators. Many also referred to the stereotypes projected by the media. Several workers concluded that they were perceived by society as criminals.

Remarks regarding this phenomenon were expressed in three ways. Many denounced the injustice of being treated like criminals, of being the subject of suspicion, and at times of even feeling as if they were being punished simply filing a CSST claim or for having suffered an employment injury. As explained by one worker:

"Me, I've thought about this a little bit, and... I've got a friend who is in the police in Montréal and he said, 'You know, there are a lot of fraud artists!' I said, 'Yes, me for example, I spent all winter watching the war in Iraq on television. They went to war because they say there are chemical weapons and all of that; that was their reason. But I think that the CSST, to avoid accepting your claim, they say: 'There are a lot of fraud artists!' You understand? 
But that's not true! Because it's people like me who are hung out to dry, damn it! And I'm not a fraud artist! Do you understand?"

Others felt it a great injustice that they as individuals were treated like criminals, but they found it legitimate that other injured workers were treated this way by the CSST, the employer or society in general:

"Q: What did you think of the CSST before you had your accident?

"A: Before [...] what I knew a lot about was largely with regards to back pain. And a back, it's like the guy in the end, he's on CSST because he's got back pain, but he's skidooing, and he's 4-wheeling! You know, at a certain point! You've got to understand [the insurer's suspicion]! That, I'm in full agreement with that! You know that's playing both sides a bit! But in my case, it's still... my injury is obvious [loss of an eye]. I never thought I'd have problems like this."

Finally, some completely espouse the widespread social prejudices regarding injured workers, and as a result feel guilty for having humiliated their family by having a work injury.

These prejudices regarding injured workers, often shared by the injured workers themselves regarding other injured workers, are widespread in their social circle and contribute to the victim's social isolation. As one lawyer explained:

"I often have people come into my office, and they say to me, 'It's my first time on CSST.' It's the social prejudice. They feel bad from the outset filing a claim and receiving CSST. The people who say that to me and who are collecting social assistance as well, they'll say, 'And social assistance, it's the first time I've been on social assistance in my life.' That's common with people in their late forties, fifty years old, you know those that have always worked, who in some cases have children at university. Immigrants, I think it's even more difficult for them, because they came here and they want the best for their children. Sometimes I find these people to be very fragile; they are really sensitive; even with me, one senses they are embarrassed. So, I imagine that faced with their workmates, they...; sometimes even in the workplace there is prejudice, 'She or he doesn't want to come to work.' One time I visited a worksite, and there were workers, you could feel it, they looked at the lady as if to say, 'What's she doing bringing her lawyer to our job?' You feel it... there are prejudices and those prejudices...; co-workers, the employer, it's obvious; not all employers but some employers, it's obvious. Us, what we see, are the cases in which there are problems. The problems are with employers; they aren't only with the CSST caseworker."

Some workers developed strategies of self-abnegation to protect their self-esteem and reputation, abstaining from claiming for some of the eligible expenses or returning to work prematurely in order to be perceived as a 'good' or 'honest' worker. These strategies are similar to those described in an Australian study of injured workers (Sager \& James, 2005).

In the course of our study it became clear that among disability management practices that are currently in use, some were particularly stigmatizing. A recently published law book directed at managers interested in preventing workers' compensation "abuse" (Lafond, Bergeron, \& Laliberté, 2006) pictures on its cover a cartoon of a worker whistling as he removes his cast from the trunk of his car while the overworked disability manager of the employer has his back turned. Several strategies are proposed to employers, including video-surveillance. Video-surveillance by private detectives, paid for by the compensation board or the employer to spy on injured workers, was particularly hurtful to injured workers we interviewed, whether or not they had personally been targeted by a detective (Lippel, 2003; Lippel, 2005). The legitimacy of these practices is referred to in the legal literature directed at lawyers working for employers (Lafond et al., 2006; Pedneault, Bernier, \& Granosik, 2002) and has some foundation in the case law. In the words of a Superior Court judge, the fear of violation of privacy was an appropriate tool to keep workers in line and prevent fraud:

"Covert shadowing and surveillance, or their spectre, particularly when practised without warning, constitute a pragmatic method to promote respect for the law. ${ }^{8}$ " [our trans.]

The attitude of the Québec courts (Lippel, 2005) is surprisingly supportive of these practices, given that the right to privacy is enshrined in both the Québec Civil Code ${ }^{9}$ and the Québec Charter of Human Rights and Freedoms. ${ }^{10}$ Were the workers to have been suspected of a crime, the video-surveillance evidence would have been inadmissible without a

\footnotetext{
${ }^{8}$ Duguay v. Plante et le Tribunal du travail, (July 16th 2001), 500-05-064211-012, D.T.E. 2001 T-1023,

(C.S.Q.). ${ }^{9}$ S.Q. 1991 , c. 64 , s. 35.

${ }^{10}$ R.S.Q. c. C-12, s. 5.
} 
warrant, ${ }^{11}$ yet warrants are never obtained in the context of workers' compensation. Ironically, courts conclude that violation of privacy in an administrative law context is acceptable, because the sanction does not have the stigmatizing effect of a criminal conviction. ${ }^{12}$

The effect of video-surveillance is devastating for several reasons. It confirms the stereotype that injured workers are dishonest and should be treated as criminals. It thus contributes to diminished self-esteem associated with injured worker status and, perhaps most importantly, from a disability prevention perspective, it discourages workers from attempting movements that could reduce long term disability. The message they retain is that they should not be seen to move at all.

"It went on for a month, a month and a half, that kind of surveillance. The effect? I hid for 3 years. I was a shut-in; there was no way they were going to film me. I went into the basement, and there I made a group of friends by short-wave radio. A friend that I don't see, I only hear his voice, he never sees me, he can't judge me. I only spoke by radio and nobody saw me take a step and I stayed home; that lasted 3 years. Even now, if I see a vehicle parked for too long where it doesn't belong, it's not good..., right away I feel like I'm under surveillance. There's no reason; my case with the CSST is resolved, but the feelings are still there. You can't believe what it's like to be under surveillance if it's never happened to you. It destroys a person like you can't imagine! Because it's a lack... it's a lack of respect! It gets in; it's a bit like it gets inside of us. And somebody who is under surveillance, it's as if... the person under surveillance is a liar, is a cheat. The lowest of the low in our society, that's what you are if you're under surveillance... That pushed me almost to suicide, all of that stuff $[\ldots]$ ".

\subsubsection{Imbalance of power}

We met with many workers who told us that at each step in the process they "had to fight" against "a big machine," "like David against Goliath," that they were confronted by the "scheming" "of the employer and the CSST," "of the union, the CSST and the employer", "of the CSST and the CLP," of "the employer's physicians and the CSST," of "all of the lawyers and the CLP conciliator". In analysing the circumstances to which the people were referring when they spoke of the imbalance of power, we came to understand the degree to which the workers felt that a multitude of players were involved in making their experience more difficult. It isn't necessarily the CSST as an institution that they are talking about when they speak of a "big machine," but filing a claim with the CSST leads to the intervention of a number of parties, setting in motion a series of "big machines" that seek to control the injured worker, control his future, control costs, control his body, control his appeal, control the return to work process, control his behaviour at work, or at occupational therapy, or at the doctor's office, and, in the case of clandestine surveillance, control his personal life and that of his family. Many interviewees described an enormous imbalance between the worker's resources and those of the other players involved in the system, notably those of the employer and the CSST. When one or the other of these players contests the claim, there is already a power imbalance. The employer has greater economic resources and both the worker and his colleagues are legal subordinates. The CSST also has significant resources, as well as access to information unavailable to the worker.

The issue of power imbalance in the legal context is not new, nor is it exclusive to the field of workers' compensation. Galanter has described the division of the legal profession in the United States, showing the importance of disparities between the means at the disposal of those who represent large organisations and those who represent individuals (Galanter, 2005-2006). In Galanter's terms, injured workers are "one-shot players", while the CSST and most employers are "repeat-players" (Galanter, 1974). In the context of workers' compensation, power imbalances may be even more pronounced, given that many workers have no legal representation at all. While power imbalance clearly has a significant impact on case outcomes, it also can affect the health of litigants.

In our study, the health effects of this imbalance are reflected in the words of this woman:

"I [received] a paper to return to work...; I held two jobs. So, I was juggled between two bosses. So between two physicians and two bosses and the CSST, I was in the middle of the five. Five masters. I became very depressed; I consulted a psychologist..."

\footnotetext{
${ }_{11}^{11}$ R. v. Wong, [1990] 3 S.C.R. 36.

12 Comité paritaire de l'industrie de la chemise v. Potash, [1994] 2 S.C.R. 406.
} 
When both the CSST and the employer oppose the worker's claim, particularly when the employer and the CSST appear together at an appeal hearing, each represented by lawyers and medical experts, the imbalance is even more striking. One worker we interviewed had been subjected to two separate episodes of clandestine surveillance by private detectives, one paid for by the CSST and the other by the employer.

Clearly the adversarial climate that governs the workers' compensation process in Québec is a key factor in the undermining of workers' health. Having to fight all the time, continually living with the stress of multiple contested decisions, as every CSST decision on any issue as well as every report from the attending physician can be the basis of a distinct legal challenge by the employer or the worker, all may interfere with the healing process. Workers told us that the experience of a "CSST beneficiary" was sometimes more difficult than that of a person injured outside of the workplace.

"I felt that they were doing everything in their power to undermine me. I saw the complicity between the employer, the CSST and the arbitrator... I saw that they're all on the same side. I finally understood that! I saw that it's one big gimmick. And it's that that... that's where I got destabilized. It doesn't help your morale, when you see that everyone's against you."

Some injured workers count on the CSST to recreate a balance of power between the worker and the employer. There are times when these hopes are fulfilled, but often they are disappointed by the passivity or the complicity of the CSST with the employer, particularly when the time comes for the worker to return to work. Denial or termination of benefits is often the event that triggered a reaction in the self perception of the workers interviewed, who went from seeing themselves as claimants to seeing themselves as victims of a system.

\subsubsection{Access to social support}

Most of the workers we interviewed had undergone trying experiences both because of their injuries but also because of the challenges intrinsic to the compensation process. Some came out of the process relatively unscathed, while others became permanently disabled as a result of psychiatric problems attributable more to the process than the injury. One of the determinants of health outcomes was the presence or absence of a relationship with a person who was knowledgeable about the process and in whom the worker had confidence. When workers felt supported by a doctor, a lawyer, an injured workers' association, a well informed union representative, a CSST caseworker, a sympathetic employer, a colleague, a spouse or other injured workers, the frustrations caused by the process had a less negative effect on their health. The therapeutic effect of the support was maximized when it came from a person in a position of power, because it served not only as social support but as a source of technical reassurance. Injured workers we interviewed felt vulnerable because of lack of information. When the worker was totally isolated, as many were, the imbalance and the stigmatization have devastating effects. When support was available, the compensation process could have a therapeutic effect, as in the case of a worker who had been the victim of violence at work:

"The Montréal CSST caseworker, I could tell by her behaviour, her actions, that she understood. After that... I had a caseworker in Québec City who had experienced aggression... and who wasn't... the social worker type, but she was OK. And then after that, I had a caseworker who was a social worker, and who had a more social work approach. She was young and, I believe, she had values, and... in any case, an understanding of social problems and... wasn't a bureaucrat... you know... Now I have a new one who previously dealt with... trauma following bank robberies. That means that she has had clients with post-traumatic stress disorder. So I think she understands!"

In summary, stigma, imbalance of power and lack of support were the key factors associated with workers' selfreported mental health problems. We will now discuss their sources.

\subsection{Steps in the process and relationships that contribute to the worker's experience}

In order to understand the context of the worker's experience it was necessary to understand the legal mechanisms governing the workers' compensation process as well as both the prescribed and the actual roles of the different actors encountered by the workers. We looked at each separate step in the process and each actor involved. The following were among the steps and actors subject to a separate analysis, and, although to do justice to each goes beyond the scope of this article, we note them here in a summary fashion, as they all proved relevant. 


\subsubsection{How the injury happened}

When the injury was caused by employer negligence, or when occupational health and safety rules had been violated, workers were often angry and the emotions associated with the employer were necessarily key to both the claims and the return to work process. Unlike claimants in another of our studies looking at Québec's no-fault automobile insurance system (Lippel \& Fabris, 2005), no injured worker expressed the desire to sue the employer, however the fact that circumstances surrounding the employment injury were judged to be irrelevant by the CSST, unless they could serve to deny the worker's claim for reasons of medico-legal causation, was a source of anger for many of those interviewed. Nonetheless, the no-fault nature of the workers' compensation system clearly allows workers to avoid some of the anti-therapeutic consequences identified in association with the tort system (Pryor, 2006; Shuman, 2000). The fact that the worker can feel blamed in the process, while the fault of the employer is not at issue, contributes to both feelings of stigma and power imbalance.

\subsubsection{Access to health care and other relationships with doctors}

Initial acceptance of a workers' compensation claim opened doors to healthcare that were otherwise not available in a timely manner. The corollary was that delayed acceptance of a claim had adverse health effects. Access to health services - including physiotherapy, osteopathy, pain clinics, psychologists and acupuncture - was enhanced by the acceptance of a claim, an aspect much appreciated by the workers.

As in other jurisdictions (Lax \& Manetti, 2001), doctors are perceived as reticent to treat injured workers, and some workers interviewed felt it safer to not mention that their injury was caused by work if they wanted to access treatment. Information from group interviews in other Canadian provinces showed that, if anything, this phenomenon was even more prevalent in British Columbia and Ontario, because the compensation boards in those provinces were not bound by the opinion of the treating physician, and doctors, and even nurses, working for the compensation board, could overrule the opinion of the treating physician. While the treating physician's opinion holds more weight in Québec, it can be questioned through a medical arbitration procedure that often leads to multiple medical exams. One worker interviewed had undergone twenty-three medical evaluations in the context of the compensation process. None of these exams had a therapeutic goal, and the obligation to continually revisit a traumatic experience at the bequest of physicians working for the board or the employer had no therapeutic value.

The role of doctors as gatekeepers was seen, in some cases, to undermine the therapeutic relationship, and some workers reported sensing that their treating physicians, who they had known for years, showed new feelings of mistrust and distanced themselves from the patient. As trust is a key factor in the therapeutic relationship (Hall, 2002-2003), compensation systems should ensure that the adjudication process does not undermine that relationship, as the introduction of mistrust can lead to unnecessary negative health effects that contribute to disability.

Difficulties in accessing health care contribute to the feeling of being stigmatized; undermining of the relationship with the doctor deprives the worker of a source of social support and in some cases contributes to the feeling of power imbalance.

\subsubsection{The claims adjudication process}

The experience of this step in the process is strongly dependant on the relationship with the front line adjudicator, but is also dependant on access to accurate information, access to the adjudicator, and local case management practices. Important regional differences were identified, with practices in poorly managed regional offices having particularly negative effects on the claimants. As one lawyer told us: "when the [regional office of the] CSST is sick, our people are sick". Some of the most damaging practices included an institutional culture of suspicion and disrespect, presuming a worker to be a malingerer, clandestine surveillance of workers (Lippel, 2003; Lippel, 2005) and file rotation between caseworkers to ensure that they didn't develop sympathy for the claimants. Workers deplored having to be proactive in accessing information, and many said they felt insecure because if they did not ask the right question, they wouldn't access benefits or services to which they were entitled. The clarity of the language used to communicate in writing with workers left much to be desired; often the language was technical and held no meaning for the worker. This was the case with workers who spoke and read French or English well; the situation was far worse for those who had literacy problems or whose first language was neither French nor English (English speaking workers received correspondence in English). The literature underlines the importance for insurers to provide a personalized and supportive service to claimants, even in those cases where a requested service is denied (Cerminara, 2005), and while there was potential for 
this form of social support, it did not often materialize for the subjects in this study. The wisdom of this approach was confirmed by those who benefited from a positive relationship with the caseworker. Those who did not saw the caseworker as a source of prejudice and as part of the power imbalance.

\subsubsection{The rehabilitation process}

Legally, the right to vocational rehabilitation exists in Québec since 1985, but it is reserved for those whose employment injuries have left them with an impairment that affects their ability to return to pre-injury employment. In recent years there has been a strong economic incentive placed on employers to reintegrate injured workers, sometimes before the injuries have healed or reached a therapeutic plateau. While this is a positive step in some cases, in others it has led to unreasonable decisions driven by economic incentives rather than sound practice, and several of the workers we interviewed suffered recurrences of their injury after initial return to work. The economic incentives designed to encourage employers to reintegrate workers have also led to an increase in litigation, and not only workers but employers who want to avoid the costs of vocational rehabilitation now contest not only the initial claim, but also the diagnoses, the description of functional limitations, permanent impairment, and the "appropriate employment" defined in the rehabilitation plan. Rehabilitation counsellors, occupational therapists and human factors professionals may all become key players in the experience of workers who are involved in the rehabilitation process.

\subsubsection{Experience of appeal hearings}

As we saw from the appeal statistics quoted earlier, Québec's workers' compensation system is one of the most adversarial in Canada, so it is not surprising that the experience of litigation was significant for many workers (Lippel, 2006). One of the facets of the process that was identified as having a favourable effect on the workers' health was that part of the appeal hearing where the workers could be said to have had their day in court. This study showed that procedural justice needs could be met in a no-fault system by an understanding decisionmaker, and that it was not necessary that the court attribute blame (Shuman, 1994) for these justice needs to be met. Although it was often in the context of cross-examination that workers felt they were treated like criminals, many workers identified the understanding attitude of the appeal commissioner as being one of the most therapeutic aspects of the process. This was said not only by those who had won their appeals, but by some who had lost and who were dissatisfied with most aspects of the process. When a person in authority hears them out and tells them they are believed, they regain some of their dignity and lost self esteem; out of court settlements during the conciliation process did not provide this satisfaction. Both these findings are reflected in the literature on tort litigation as well (Shuman, 2000).

While the hearing was often the most flagrant example of power imbalance, it was in many cases also the primary source for social support and validation, which did much to neutralize the stigmatization from other sources. Lawyers in the process were sometimes the source of great mental distress, the posturing typical of adversarial justice being a source of incomprehension and in some cases devastation. Nonetheless, the social support gleaned from the worker's own lawyer or union representative was often identified as being protective of peace of mind.

\subsubsection{Experience of receiving or not receiving compensation}

When support was forthcoming, the economic and medical needs of the worker were at least partially met, which had a favourable effect on individual and family stress levels and a favourable impact on the worker's physical and mental health. When benefits were denied or perceived to have been terminated prematurely, the worker rapidly assumed the role of a litigant in conflict with the many actors who could oppose each aspect of the claim. It was then that the imbalance in power became most obvious. Often it was only when benefits were refused that the importance of accessing benefits was explicitly described by our subjects. In comparing those who received benefits with those who didn't, we identified several indicators of well-being associated with receiving benefits. Those who accessed salary replacement did not complain of re-injury after returning to work prematurely and several felt relieved that they could continue to support their families. In contrast, those who did not receive salary replacement benefits in a timely manner, either because their claim was denied or because their eligibility was not recognized for the full period of disability, expressed many negative emotions including anxiety over inability to make payments on their home and vehicle, property which was sometimes confiscated because of failure to make payments, humiliation when they had to resort to social assistance, and fear with regard to the effect of their injury on their families. 


\section{Discussion}

Many aspects of our findings were very similar to those of researchers in other jurisdictions. In a study of injured workers in South Australia, Roberts-Yates (2003, p. 904) noted that "A considerable percentage of the interviewees concluded that being on WorkCover is in fact the greatest disability of all and a major source of stress. Many respondents were troubled by the reinforcement of stereotypes with workers portrayed as abusing the system." This was a key finding of our study, and a key finding of Eakin, MacEachen, and Clarke (2003) who coined the term "discourse of abuse" to describe a similar phenomenon identified in their study of Ontario injured workers and their employers involved in the return to work process.

\subsection{Feeling like an object}

As in Québec, workers in Australia found that the "process lacks a total person response" (Roberts-Yates, 2003, p. 900): caseworkers were not proactive with information that could help the worker make informed choices (p. 905). Other key issues identified in the Roberts-Yates study were adversarial relationships, and the need for social support (Roberts-Yates, 2003, p. 904), all elements included as key conclusions of our study (Lippel et al., 2005).

Despite different languages and huge geographical distances, the similarities in the descriptions given by workers of their experience of the process are sometimes uncanny. In Roberts-Yates study, an Australian worker described how she felt during a meeting between rehabilitation professionals and her employer: "I felt like a number with skin on". In our study, a worker described the return to work negotiations between her employer and a rehabilitation counsellor in these terms:

"She explained to him that he would have to pay me for the rest of the year, and that his insurance would go up; she explained all that to him in front of me... So you realize that you're just a tiny object... It was like saying, 'Put her somewhere in a chair, at least it'll cost you less. You've got to take her back! Wait a couple of months then get rid of her!' That's what it meant to me."

\subsection{Lack of sympathy}

Candace Clark, in her study of sympathy (Clark, 1997) has described unsympathetic sub-cultures where to lack sympathy is the norm and, for some subjects she interviewed, the workplace is seen as an inappropriate place to show sympathy (pp. 68-69), while another subject noted that work in insurance is not conducive to sympathy (p. 71). She notes that "giving sympathy bestows moral worth on the recipient, and withholding sympathy denies worth" (Clark, 1997, p. 22) and adds that "we may make little effort to empathize with the problems of the poor, drug addicts, prostitutes, and others to whom our society accords low esteem" (p. 40). This could explain why institutional actors in the compensation process are reported to show so little sympathy for the injured worker. A useful concept discussed by Clark is that of the "belief in a just world": "Belief in a just world' is a mental set that entails evaluating people as unworthy simply because their circumstances are bad" (pp. 46-47). Quoting from a study by Lerner and Simmons (1966), in which, by experimental design, some subjects were in a position to compensate a hapless victim while others were not, those who could not compensate the victims distanced themselves from the victim and perceived her as unworthy, a position that was not taken by those who were free to offer compensation. "One way to escape dissonance and create cognitive balance was to perceive the plight as not so bad" (p. 48). Another was to conclude that the victim was responsible for his plight (p. 101). The "just world bias" has been used to better understand criminal behaviour motivated by hate crimes (Dharmapala, Garoupa, \& McAdams, 2006), and degree of support for social programs (Appelbaum, Lennon, \& Aber, 2006) and is a useful concept for the study of victimisation.

Other explanatory factors for the dearth of sympathy for some of the injured workers interviewed could be that people with chronic illness are known to receive less sympathy than those with an intermediate-range acute illness (Clark, 1997, p. 254). “...pursuing the ideas of emotional culture and socioemotional economy makes it more clear why the disabled, the chronically ill, the elderly, the homeless, and AIDS sufferers get less sympathy than their circumstances would seem to warrant. Since these groups often have limited cultural and social capital, they may have little to offer in the socioemotional economy." 
Some of the workers we interviewed showed sympathy for their CSST caseworker, and had fewer problems. Applying Clark's analysis, this could be explained either because this allowed them to reduce their anger by reducing the importance of that person in their minds (p. 240) or because their empathetic attitude to the caseworker softened the caseworker's attitude to the worker, perhaps an illustration of the reciprocity patterns described by Clark (p. 159).

\section{Conclusion}

This study was designed to shed light on the experiences of injured workers who seek compensation, but results do not reflect the situation of a representative sample of all injured workers and cannot be generalized to the injured worker population of Québec. Limitations of the study include possible bias in the recruitment process, given that participants self-selected to tell their stories, and lack of objective measures of health outcomes attributed to the process by the workers. Nonetheless, detailed information as to the perceptions of the process by the workers allows a better understanding of the dynamics that may contribute to disability in the minority of injured workers who develop long term disability after experiencing a work injury.

The results of this study have implications both for research and for policy. Among the implications of our findings for future research on work disability, our results suggest that access to compensation, litigation and the role of lawyers should be studied in a more refined way than as simply a binary variable to be considered in the prediction of health outcomes. There are technical reasons that may increase costs of compensation payments for disability when litigation is involved. For instance, if a claim is only accepted in appeal, perhaps years after the original claim was filed, access to health care and rehabilitation services is not provided in a timely manner and disability may indeed be increased because of the initial refusal. It is not the litigation that leads to the disability in this case, but the unwarranted refusal of the claim. Contrary to what is sometimes presumed, the presence of a lawyer representing a worker may be protective of the claimant's health. We found, as have others (Pryor, 2006), that lawyers often provide not only technical but social support. Legal representation is often an indicator of a litigious claim, and the litigation can contribute to prolonging disability not because of a supposed economic incentive to not heal, but because of various stressful events to which the worker is exposed because of the litigation (Shuman, 2000). To be useful, epidemiological studies that consider litigation or compensation as a factor need to provide more refined measurements of "litigation" and more nuanced conclusions with regard to the effect of compensation or litigation on outcomes.

Research teams interested in disability prevention should include researchers familiar with the specific compensation system applicable to the population studied, as an understanding of the system can shed light on the relationships and mechanisms by which an apparent adverse health effect is produced. Having legal specialists in our research team proved to be very useful in interpreting the data, as workers are often confused about what has happened to them and diagnosis of the problems that lead to this confusion requires knowledge of the system being discussed. Sometimes the workers did not understand the events they were describing, and it was this misunderstanding that contributed to their vulnerability. Knowledge of the system studied was key in the development of recommendations.

It goes beyond the scope of this article to propose a broad range of solutions to the many problems of the workers' compensation system identified in our study, yet it is possible to look more closely at specific facets of the system that merit scrutiny. We identified three primary causes of distress: stigma, power imbalance and lack of social support, and each of these elements needs to be addressed if system-generated disability is to be reduced.

To reduce the stigma associated with claiming workers' compensation, stereotyping of injured workers as "profiteers" needs to stop. The Québec compensation system, like many North American systems, uses experience rating as an incentive to employers to manage disability, and this also encourages employers to hire lawyers and engage in management practices that may contribute to adverse health effects. Those responsible for compensation systems should be aware of potential perverse effects of disability management systems put into place to reduce costs without reducing disability. Promoting stigma as a cost containment tool, as is illustrated by recourse to video-surveillance, may be cost-effective in the short term, serving to discourage workers from claiming compensation and getting them back to work more rapidly, but it undermines the credibility of the compensation system itself, while generating new costs to society, providing new sources of ill health that burden both the healthcare and the social security systems, as well as harming those the system was designed to protect. To do no harm, the system needs to insure that the worker's dignity is preserved (Jones, Burström, Marttila, Canvin, \& Whitehead, 2006).

Power imbalance (Galanter, 1974) is intrinsic to the workers' compensation system: employers will always have more economic power than workers and state insurers have a monopoly on information regarding their own system. 
Nonetheless, there are ways in which power imbalance can be reduced, and some strategies would also contribute to social support of workers. Institutions financed by the compensation boards but independent from the boards provide competent representation to injured workers, without charge, in most Canadian provinces, although not in Québec. ${ }^{13}$ Such services could help in reducing the imbalance of power between the Québec workers and other players.

Workers' compensation systems are designed to get away from the adversarial nature of the tort justice system yet they have reproduced many of the flaws of the tort system. Even in tort law, the adversarial nature of proceedings is currently critiqued by many legal scholars (Carson, 2003; Coughlan, 1993; Mackenzie, 1996), and administrative tribunals should shun litigious behaviour that is becoming the rule rather than the exception. Adversarial practices in appeal tribunal proceedings can be more stringently proscribed, tribunals can be more proactive in insuring a balance between opposing parties and approaches to cross-examination could be more relevantly regulated (Carson, 2003). The compensation system should be designed to ensure there are economic consequences if management practices undermine workers' health. Currently most Québec case law concludes that disability attributable to the compensation process is non-compensable, and this sends the wrong message to employers and the CSST (Lippel, 2006).

The fact that design and implementation practices of social security systems can affect the health of those they are meant to help is well known to those who study health care (Cerminara, 2005; Hall, 2002-2003), and social welfare legislation (Jones et al., 2006; Wilkinson, 1996), yet these issues are rarely discussed with regard to disability insurance systems and workers' compensation. This study confirms that they are just as relevant in this context and require attention of both researchers and policy makers.

\section{Acknowledgements}

The author wishes to acknowledge the financial support of the Social Sciences and Humanities Research Council of Canada and the research assistance support of Joseph Caron, Marie-Claire Lefebvre, Chantal Schmidt and Leandro Steinmander who all contributed to the successful completion of the study. The Union des travailleuses et travailleurs accidentés de Montréal and the Assemblée des travailleuses et travailleurs accidentés du Québec, community organisations representing the interests of injured workers, were research partners in this study and contributed to the framing of the research questions, the recruitment of some of the participants and the validation of the results. The participants in the study were generous with their time and their stories, and their contribution permitted us to better understand the experience of injured workers.

\section{References}

Appelbaum, L. D., Lennon, M. C., \& Aber, L. (2006). When effort is threatening: The influence of the belief in a just world on Americans' attitudes toward antipoverty policy. Political Psychology, 27(3), 387-402.

Baril, R., Clarke, J., Friesen, M., Stock, S., \& Cole, D. (2003). Management of return to work programs for workers with musculoskeletal disorders: A qualitative study in three Canadian provinces. Social Science \& Medicine, 57(11), 2101-2114.

Baum, F., MacDougall, C., \& Smith, D. (2006). Participatory action research. Journal of Epidemiology and Community Health, 60, 854-857.

Beardwood, B. A., Kirsh, B., \& Clark, N. J. (2005). Victims twice over: Perceptions and experiences of injured workers. Qualitative Health Research, 15(1), 30-48.

Braun, R. M., Doehr, S., Mosqueda, T., \& Garcia, A. (1999). Effect of legal representation on functional recovery of the hand in injured workers following carpal tunnel release. Journal of Hand Surgery, 24A, 53-58.

Carson, D. (2003). Therapeutic jurisprudence and adversarial justice: Questioning limits. Western Criminology Review, 4(2), $124-133$.

Cassidy, J. D., Carroll, L. J., Côté, P., Lemstra, M., Berglund, A., \& Nygren, A. (2000). Effect of eliminating compensation for pain and suffering on the outcome of insurance claims for whiplash injury. New England Journal of Medicine, 16, 1179-1186.

Cerminara, K. L. (2005). Dealing with dying: How insurers can help patients seeking last-chance therapies (even when the answer is "no"). Health Matrix, FS, 15, 285-328.

Clark, C. (1997). Misery and company: Sympathy in everyday life. Chicago: University of Chicago Press.

Commission de la santé et de la sécurité du travail. (2005). Rapport annuel d'activités, 2004. Québec: Gouvernement du Québec.

Commission des lésions professionnelles. (2000). Rapport annuel de gestion 1999-2000. Québec: Gouvernement du Québec.

Commission des lésions professionnelles. (2005). Rapport annuel de gestion 2004-2005. Québec: Gouvernement du Québec.

Coughlan, S. G. (1993). The "adversary system": Rhetoric or reality? Canadian Journal of Law and Society, 8(2), 139-169.

Dembe, A. (1999). Social inequalities in occupational health and health care for work-related injuries and illnesses. International Journal of Law and Psychiatry, 22(5-6), 567-579.

\footnotetext{
13 http://www.gov.mb.ca/labour/standards/wao/links.html, consulted November 24th, 2006.
} 
Dembe, A. (2001). The social consequences of occupational injuries and illnesses. American Journal of Industrial Medicine, 40, $403-417$.

Desrosiers, N., \& Langevin, L. (1998). L'indemnisation des victimes de violence sexuelle et conjugale. Cowansville, Qc: Éditions Yvon Blais.

Dharmapala, D., Garoupa, N., \& McAdams, R. H. (2006). The Just World Bias and Hate Crime Statutes. University of Illinois legal working paper series, University of Illinois law and economics working papers. Working paper, vol. 60. http://law.bepress.com/uiuclwps/papers/art60

Eakin, J. M. (2005). The discourse of abuse in return to work: A hidden epidemic of suffering. In C. L. Peterson, \& C. Mayhew (Eds.), Occupational health and safety: International influences and the «new» epidemics (pp. 159-174). Amityville, New York: Baywood Publishing co. Inc.

Eakin, J., MacEachen, E., \& Clarke, J. (2003). 'Playing it smart' with return to work: Small workplace experience under Ontario's policy of selfreliance and early return. Policy and Practice in Health and Safety, 1(2), 19-42.

Fougeyrollas, P., Lippel, K., St. Onge, M., Gervais, M., Boucher, N., \& Bernard, N. (1999). La compensation des coûts supplémentaires au Québec: Pour une couverture équitable des besoins liés aux déficiences, aux incapacités et aux situations de handicap. Québec: Laboratoire de recherche sociale de l'Institut de réadaptation en déficience physique de Québec.

Galanter, M. (1974). Why the "haves" come out ahead: Speculations on the limits of legal change. Law and Society Review, 9(1), 95-160.

Galanter, M. (2005-2006). Planet of the APs: Reflections on the scale of law and its users. Buffalo Law Review, 53(5), $1369-1418$.

Glaser, B., \& Strauss, A. L. (1967). The discovery of grounded theory: Strategies for qualitative research. Chicago: Aldine.

Hall, M. A. (2002-2003). Law, medicine and trust. Stanford Law Review, 55(2), 463-528.

Ison, T. G. (1986). The therapeutic significance of compensation structures. Canadian Bar Review, 64, 605-637.

Jones, C., Burström, B., Marttila, A., Canvin, K., \& Whitehead, M. (2006). Studying social policy and resilience to adversity in different welfare states: Britain and Sweden. International Journal of Health Services, 36(3), 425-442.

Kirsh, B., \& McKee, P. (2003). The needs and experiences of injured workers: A participatory research study. Work, 21(3), $221-231$.

Lafond, R., Bergeron, C., \& Laliberté, M. A. (2006). Lésions professionnelles: contrôle de l'abus et des coûts: tout ce que l'employeur doit savoir. Cowansville, Qc: Éditions Yvon Blais.

Lax, M., \& Manetti, F. (2001). Access to medical care for individuals with workers' compensation claims. New Solutions, 11(4), 325-348.

Lerner, M. J., \& Simmons, C. (1966). The observer's reaction to the 'innocent victim': Compassion or rejection? Journal of Personality and Social Psychology, 22, 202-210.

Link, B. G., \& Phelan, J. C. (2001). Conceptualizing stigma. Annual Review of Sociology, 27, 363-385.

Lippel, K. (1986). Droit des accidentés du travail à une indemnisation: Analyse historique et critique. Montréal, Qc: Éditions Thémis.

Lippel, K. (1999a). Workers' compensation and stress: Gender and access to compensation. International Journal of Law and Psychiatry, 22(1), 79-89.

Lippel, K. (1999b). Therapeutic and anti-therapeutic consequences of workers' compensation systems. International Journal of Law and Psychiatry, $22(5-6), 521-546$

Lippel, K. (2003). Private policing of injured workers: Legitimate management practices or human rights violations? Policy and Practice in Health and Safety, 1(2), 97-118.

Lippel, K. (2005). Les enjeux juridiques et sociaux du recours aux enquêteurs privés pour surveiller les victimes de lésions professionnelles. Revue canadienne de criminologie et de justice pénale/Canadian Journal of Criminology and Criminal Justice, 47(1), 127-173.

Lippel, K. (2006). L'expérience du processus d'appel en matière de lésions professionnelles telle que vécue par les travailleuses et les travailleurs. Développements récents en santé et sécurité du travail 2006 (pp. 119-180). Cowansville, Qc: Éditions Yvon Blais.

Lippel, K., \& Fabris, S. (2005). Les expériences de personnes accidentées qui réclament auprès d'une compagnie publique d'assurances et l'impact de ces exigences sur la santé. Congrès Québécois de réadaptation en traumatologie, Montréal, 17-18 November, 2005.

Lippel, K., Lefebvre, M. -C., Schmidt, C., \& Caron, J. (2005). Traiter la réclamation ou traiter la personne? Les effets du processus sur la santé des personnes victimes de lésions professionnelles.Montréal, Qc: Service aux collectivités de l'UQAM. http://www.juris.uqam.ca/dossiers/ traiter_reclamation.htm

Lippel, K., Lefebvre, M. -C., Schmidt, C., \& Caron, J. (2007). Managing claims or caring for claimants: Effects of the compensation process on the health of injured workers. Montréal, Qc: Service aux collectivités de l'UQAM.

Mackenzie, G. (1996). Breaking the dichotomy habit: The adversary system and the ethics of professionalism. Canadian Journal of Law and Jurisprudence, $\operatorname{IX}(1), 33-50$.

Pedneault, J. -F., Bernier, L., \& Granosik, L. (2002). Les droits de la personne et les relations de travail. Cowansville, Qc: Éditions Yvon Blais.

Pryor, E. S. (2006). Noneconomic damages, suffering, and the role of the plaintiff's lawyer. DePaul Law Review, 55, 563-615.

Reid, J., Ewan, C., \& Lowy, E. (1991). Pilgrimage of pain: The illness experiences of women with repetition strain injury and the search for credibility. Social Science \& Medicine, 32(5), 601-612.

Roberts-Yates, C. (2003). The concerns and issues of injured workers in relation to claims/injury management and rehabilitation: The need for new operational frameworks. Disability and Rehabilitation, 25(16), 898-907.

Roe, D., \& Ronen, Y. (2003). The troublesome aspects of psychiatric hospitalization as experienced by the hospitalized patient: A therapeutic jurisprudence perspective. International Journal of Law and Psychiatry, 26(3), 317-332.

Sager, L., \& James, C. (2005). Injured workers' perspectives of their rehabilitation process under the new South Wales workers' compensation system. Australian Occupational Therapy Journal, 52, 127-135.

Shuman, D. (1994-1995). The psychology of compensation in Tort Law. U. Kan. L. Rev., 43, 39-78.

Shuman, D. (2000). When time does not heal: Understanding the importance of avoiding unnecessary delay in the resolution of tort cases. Psychology, Public Policy, and Law, 6(4), 880-897.

Strunin, L., \& Boden, L. (2004). The workers' compensation system: Worker friend or foe? American Journal of Industrial Medicine, 45, $338-345$.

Tarasuk, V., \& Eakin, J. (1995). The problem of legitimacy in the experience of work-related back injury. Qualitative Health Research, 5(2), 204-221.

Thomason, T., \& Pozzebon, S. (2002). Determinants of firm workplace health and safety and claims management practices. Industrial \& Labor Relations Review, 55(2), 286-307. 
Tompa, E., Trevithick, S., \& McLeod, C. (2007). Systematic review of the prevention incentives of insurance and regulatory mechanisms for occupational health and safety. Scandinavian Journal of Work, Environment and Health, 33(2), 85-95.

Weisz, V., Lott, R., \& Thai, N. D. (2002). A teen court evaluation with a therapeutic jurisprudence perspective. Behavioral Sciences \& the Law, 20(4), 381-392.

Wexler, D. B. (1990). Therapeutic jurisprudence: The law as a therapeutic agent. Durham: Carolina Academic Press.

Wexler, D. B., \& Winick, B. J. (1996). Law in a therapeutic key: Developments in therapeutic jurisprudence. Durham: Carolina Academic Press. Wilkinson, R. (1996). Unhealthy Societies. London: Routledge.

Workers' Safety and Insurance Appeal Tribunal (WSIAT). (2005). WSIAT annual report 2004. Toronto, On: Government of Ontario. 